\title{
Prognostic Value of Doppler Velocimetry in Intrauterine Growth Restricted Fetuses
}

\author{
Authors \\ Dr Sushma Makhaik ${ }^{1}$, Dr Vijay Thakur ${ }^{2}$, Dr Anupam Jhobta ${ }^{3}$ \\ ${ }^{1}$ Assistant Professor Radio-Diagnosis, Indira Gandhi Medical College, Shimla HP India \\ Email:dr.sushma.makhaik@gmail.com \\ ${ }^{2}$ Associate Professor Radio-Diagnosis, Indira Gandhi Medical College, Shimla HP India \\ ${ }^{3}$ Professor Radio-Diagnosis, Indira Gandhi Medical College, Shimla HP India \\ Email:bhavuvasu@rediffmail.com \\ Corresponding Author \\ Dr Vijay Thakur
}

Associate Professor Radio-Diagnosis, Indira Gandhi Medical College, Shimla HP India

Email:vijay31thakur@gmail.com

\begin{abstract}
Introduction: Intra uterine growth restriction (IUGR) is associated with increased perinatal mortality, morbidity and impaired neurodevelopment. Doppler velocimetry can assess the fetal hypoxia thereby deciding the timing of delivery and avoiding prematurity.

Objective: To predict the perinatal outcome in IUGR fetuses by Doppler velocimetry of umbilical artery, middle cerebral artery and descending thoracic aorta and deciding the management accordingly.

Material and methods: Twenty five IUGR fetuses were subjected for Doppler velocimetry of umbilical artery (UA), middle cerebral artery (MCA) and descending thoracic aorta (DTA). S/D ratio, PI and RI were calculated to predict he fetal hypoxia.

Observations: Umbilical artery S/D ratio was increased in $52 \%$ cases, whereas PI and RI were increased in $48 \%$ and $40 \%$ cases respectively. AEDV was found in $12 \%$ and REDV in $4 \%$ cases and were associated with $75 \%$ mortality. Positive predictive value of S/D ratio of MCA for fetal distress was $75 \%$ where as it was $85 \%$ for DTA.

Conclusion: Doppler parameters can detect the changes of fetal hypoxia, so the mortality and Morbidity can be reduced by timely intervention.

Keywords/Observations: IUGR-intrauterine growth restriction. AEDV-absent end diastolic volume. REDVreversed end diastolic volume. S/D ratio-systolic to diastolic ratio. PI-pulsatility index. RI-resistive index

\section{Introduction}

Intrauterine growth restriction (IUGR) is a clinically significant problem. Perinatal mortality is 4-8 times higher in IUGR fetuses as compared to normal fetus. IUGR is defined as a condition where the weight of the fetus is below the $10^{\text {th }}$ percentile for

gestational age or at least 2 standard deviations below the mean for age. Symmetric IUGR is due to early insult like chromosomal anomaly or infection in early pregnancy. These may be genetically or constitutionally small. Asymmetric IUGR is seen in placental insufficiency.
\end{abstract}


Doppler velocimetry is a non invasive technique for assessing IUGR fetuses with hypoxia. Fetal growth failure is associated with raised placental resistance. Systolic / Diastolic (S/D) ratio, pulsatility index (PI) and resistive index (RI) are angle independent indices, calculated to know the resistance to blood flow in the artery.

The sensitivity of raised S/D ratio of umbilical artery (UA) for abnormal perinatal outcome is $66.7 \%$ in IUGR as compared to $27.8 \%$ for fetuses without IUGR. ${ }^{[1]}$ PI has better specificity than RI and S/D ratio. Reduced, absent and reversed end diastolic flow in umbilical artery is associated with poor perinatal outcome.

There is redistribution of fetal circulation with increased flow to vital organs like brain, heart and adrenals in hypoxemic fetuses. Increased PI in umbilical artery is associated with reduced PI in middle cerebral artery (MCA) which signifies brain sparing effect. Maximum reduction in PI of MCA is seen when partial pressure of oxygen is 2-4 standard deviation below the normal mean for gestational age. When the oxygen deficit increases, there is tendency for the PI in MCA to rise and this reflects development of brain oedema and high fetal mortality. ${ }^{[2]}$

\section{Material and Methods}

Doppler velocimetry was done in 25 IUGR cases having at least 4 weeks disparity in fundal height and period of gestation at 28-40 weeks gestation. Fetuses with congenital anomaly and multiple pregnancy were excluded. Doppler was done in supine position on Toshiba Corevision Prodiagnostic ultrasound system SSA- 350A machine with 3-5 $\mathrm{MHz}$ convex probe. Normal biometry was done to know the period of gestation. Umbilical artery was selected midway between fetal and placental ends. Transverse images of fetal head at the sphenoid bone were taken. Colour flow imaging was done to display the circle of willis. MCA was sampled in sylvian fissure. Descending thoracic aorta was identified in the sagittal scan of the fetus. Arch of aorta was followed downwards and DTA was sampled just above the level of thoracic diaphragm.

When 4-5 waveforms were seen on the screen, the image was frozen and measurement done with electronic calliper. S/D ratio, PI and RI were calculated by taking at least 3 readings for all the vessels sampled.

$\mathrm{PI}=$ maximum systolic velocity-end diastolic velocity/mean velocity

$\mathrm{RI}=$ maximum systolic velocity-end diastolic velocity/systolic velocity

$\mathrm{S} / \mathrm{D}$ ratio = maximum systolic velocity/end diastolic velocity

Repeat examination was done at 1-3 weeks interval depending on the parameters. The cases were followed for perinatal outcome; still birth and death due to fetal hypoxia, APGAR score of $<7$ after five minutes, admission in intensive care unit and caesarean section for fetal hypoxia.

\section{Observations}

The mean age of pregnant mothers was 24.5years. $60 \%$ mothers were primigravida.

\section{Umbilical Artery Doppler Indices}

$\mathrm{S} / \mathrm{D}$ ratio of UA was normal in $48 \%$ cases. And raised in $13(52 \%)$ cases. PI value was normal in 13 $(52 \%)$ cases and raised in $12(48 \%)$ cases, normal RI was seen in $15(60 \%)$ and raised in10 (40\%) cases.

Absent end diastolic flow was found in 3 (12\%) cases. Reversed end diastolic flow was observed in $1(4 \%)$ cases.

\section{Relationship of Doppler Parameters Of UA to Perinatal Outcome}

Eleven $(84.6 \%)$ of fetuses showing raised S/D ratio were delivered by caesarean section. Low APGAR was seen in $6(46.1 \%)$ cases. Eight neonates were admitted to ICU and 3 perinatal deaths were reported in them.

LSCS was performed for $8(66.7 \%)$ cases showing raised PI value. Low APGAR was seen in 4 (33.3\%) neonates. 5 (41.6\%) were admitted to ICU for fetal distress where as one neonate was admitted for jaundice. Perinatal deaths were reported in $3(25 \%)$ cases 


\section{JMSCR Vol||05||Issue||08||Page 26236-26241||August}

$90 \%$ of the fetuses having raised RI were delivered operatively. 5(50\%) in this group had low APGAR score, $6(60 \%)$ neonates were admitted to ICU with $2(20 \%)$ perinatal deaths.
All 3 fetuses having AEDV were delivered by LSCS and were admitted to ICU. The APGAR score at 5 minutes was $<7$ in 2 neonates. One neonate died after 5 days. REDV was present in one fetus which resulted in still birth.

Table: Showing Relationship of Doppler Velocimetry of Umbilical Artery to Perinatal Outcome

\begin{tabular}{|c|c|c|c|c|c|c|c|c|c|}
\hline \multirow{3}{*}{ Indices } & \multirow{3}{*}{\multicolumn{2}{|c|}{ Test Results }} & \multicolumn{7}{|c|}{ Perinatal Outcome } \\
\hline & & & \multirow{2}{*}{$\operatorname{NVD}(\%)$} & \multicolumn{2}{|c|}{ Operative Delivery } & \multirow{2}{*}{$\begin{array}{c}\text { Low Apgar } \\
(\%)\end{array}$} & \multicolumn{2}{|c|}{ ICU Admissions } & \multirow{2}{*}{$\begin{array}{l}\text { Still Birth } \\
\& \text { Neonatal } \\
\text { Death }(\%)\end{array}$} \\
\hline & & & & For FD $(\%)$ & For Others & & For FD $(\%)$ & For Others & \\
\hline \multirow{2}{*}{$\mathrm{S} / \mathrm{D}$} & $\mathrm{N}(\%)$ & $12(48 \%)$ & $7(58.3 \%)$ & $3(25 \%)$ & $2(16.7 \%)$ & $2(16.7 \%)$ & $2(16.7 \%)$ & $2(16.7 \%)$ & 0 \\
\hline & $\mathrm{Ab}(\%)$ & $13(52 \%)$ & $2(15.3 \%)$ & $11(84.6 \%)$ & 0 & $6(46.1 \%)$ & $8(61.5 \%)$ & 0 & $3(23 \%)$ \\
\hline \multirow{2}{*}{ PI } & $\mathrm{N}(\%)$ & $13(52 \%)$ & $5(38.4 \%)$ & $6(46.1 \%)$ & $2(16.7 \%)$ & $4(30.7 \%)$ & $5(38.4 \%)$ & $1(7.7 \%)$ & 0 \\
\hline & $\mathrm{Ab}(\%)$ & $12(48 \%)$ & $4(33.3 \%)$ & $8(66.7 \%)$ & 0 & $4(33.3 \%)$ & $5(41.6 \%)$ & $1(8.3 \%)$ & $3(25 \%)$ \\
\hline \multirow{2}{*}{ RI } & $\mathrm{N}(\%)$ & $15(60 \%)$ & $8(53 \%)$ & $5(33.3 \%)$ & $2(13.3)$ & $3(20 \%)$ & $4(26.7 \%)$ & $2(13.3 \%)$ & $1(6.7 \%)$ \\
\hline & $\mathrm{Ab}(\%)$ & $10(40 \%)$ & $1(10 \%)$ & $9(90 \%)$ & 0 & $5(50 \%)$ & $6(60 \%)$ & 0 & $2(10 \%)$ \\
\hline
\end{tabular}

$\mathrm{N}=$ normal, $\mathrm{Ab}=$ abnormal, $\mathrm{NVD}=$ normal vaginal delivery, $\mathrm{FD}=$ fetal distress, $\mathrm{ICU}=$ intensive care unit

\section{Middle Cerebral Artery Doppler Indices}

Normal S/D ratio was seen in $13(52 \%)$ cases where as $12(48 \%)$ showed decreased ratio. $8(32 \%)$ cases had normal PI and $17(68 \%)$ had decreased PI. Normal RI was found in $17(68 \%)$ and reduced RI in $8(32 \%)$ cases.

\section{Relationship Of MCA Velocimetry To Perinatal Outcome}

In 9 out of 12 cases showing decreased S/D ratio were delivered by LSCS. Low APGAR at 5 minutes was seen in $6(50 \%)$ cases and $3(25 \%)$ perinatal deaths occurred in them.

Table Showing Relationship of Middle Cerebral Artery Velocimetry to Perinatal Outcome

\begin{tabular}{|c|c|c|c|c|c|c|c|c|c|}
\hline \multirow{3}{*}{ Indices } & \multirow{3}{*}{\multicolumn{2}{|c|}{ Test Results }} & \multicolumn{3}{|c|}{ Mode Of Delivery } & \multicolumn{4}{|c|}{ Perinatal Outcome } \\
\hline & & & \multirow{3}{*}{$\begin{array}{l}\text { NVD (\%) } \\
6(46.1 \%)\end{array}$} & \multicolumn{2}{|c|}{ Operative Delivery } & \multirow{3}{*}{$\begin{array}{c}\text { Low Apgar } \\
(\%) \\
2(15.4 \%)\end{array}$} & \multicolumn{2}{|c|}{ ICU Admission } & \multirow{3}{*}{$\begin{array}{c}\text { Still Birth \& } \\
\text { Neonatal } \\
\text { Death }(\%) \\
0\end{array}$} \\
\hline & & & & For FD (\%) & For Others & & $\begin{array}{l}\text { For FD } \\
(\%)\end{array}$ & For Others & \\
\hline \multirow{2}{*}{$\mathrm{S} / \mathrm{D}$} & $\mathrm{N}(\%)$ & $13(52 \%)$ & & $5(38.5 \%)$ & $2(15.4 \%)$ & & $2(15.4 \%)$ & $2(15.4 \%)$ & \\
\hline & $\mathrm{Ab}(\%)$ & $12(48 \%)$ & $3(25 \%)$ & $9(75 \%)$ & 0 & $6(50 \%)$ & $8(66.7 \%)$ & 0 & $3(25 \%)$ \\
\hline \multirow{2}{*}{ PI } & $\mathrm{N}(\%)$ & $8(32 \%)$ & $5(62.5 \%)$ & $3(37.5 \%)$ & 0 & $1(12.5 \%)$ & $1(12.5 \%)$ & $2(25 \%)$ & 0 \\
\hline & $\mathrm{Ab}(\%)$ & $17(68 \%)$ & $4(23.5 \%)$ & $11(64.7 \%)$ & $2(11.7 \%)$ & $7(41.1 \%)$ & $9(52.9 \%)$ & 0 & $3(17.6)$ \\
\hline \multirow{2}{*}{ RI } & $\mathrm{N}(\%)$ & $17(68 \%)$ & $8(47 \%)$ & $7(41.1 \%)$ & $2(11.7 \%)$ & $3(17.6 \%)$ & $4(23.5 \%)$ & $2(11.7 \%)$ & $1(5 \%)$ \\
\hline & $\mathrm{Ab}(\%)$ & $8(32 \%)$ & $1(12.5 \%)$ & $7(87.5 \%)$ & 0 & $5(62.5 \%)$ & $6(75 \%)$ & 0 & $2(25 \%)$ \\
\hline
\end{tabular}

\section{Descending Thoracic Aorta Doppler Indices}

$8(32 \%)$ cases showed raised S/D ratio. PI and RI were normal in $23(92 \%)$ and increased in $2(8 \%)$ fetuses.
In 11 out of 17 cases having decreased PI were delivered by LSCS for fetal distress, 2 for other causes i. e hypothyroidism and breech presentation. Low APGAR was seen in $7(41.1 \%)$ cases. Nine (52.9\%) neonates were admitted to ICU and 3 $(17.6 \%)$ perinatal deaths were reported in them.

Cases having decreased RI, 7 (87.5\%) cases were delivered by LSCS, low APGAR was seen in 5 $(62.5 \%)$ neonates. Six $(75 \%)$ neonates were admitted to ICU and 2 (25\%) perinatal deaths were reported.
Relationship of Descending Thoracic Aorta Velocimetry to Perinatal Outcome

$7(87.5 \%)$ cases with raised ratio were born by LSCS. Low APGAR was seen in $3(37.5 \%)$ 


\section{JMSCR Vol||05||Issue||08||Page 26236-26241||August}

neonates. Four $(50 \%)$ neonates were admitted to ICU and 2 (25\%) were still born (fresh) 1 (12.5\%) neonate died after 5 days.

2 cases with raised P I and RI were born by LSCS, 1 $(50 \%)$ had low APGAR score and 1(50\%) was admitted to ICU, one was fresh still birth and another died after 5 days.

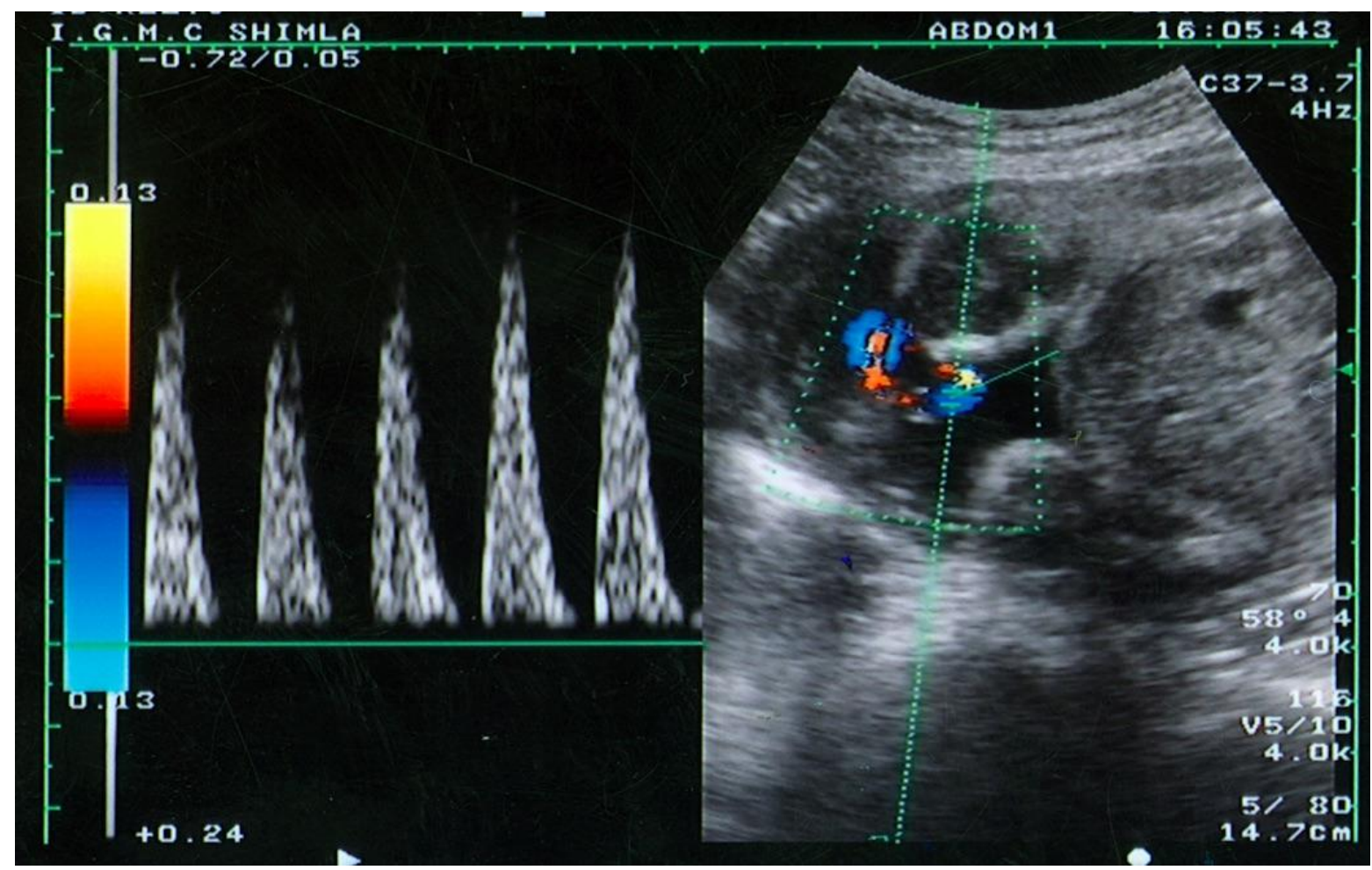

Case 1 - Umbilical artery showing absent end diastolic velocity (AEDV)

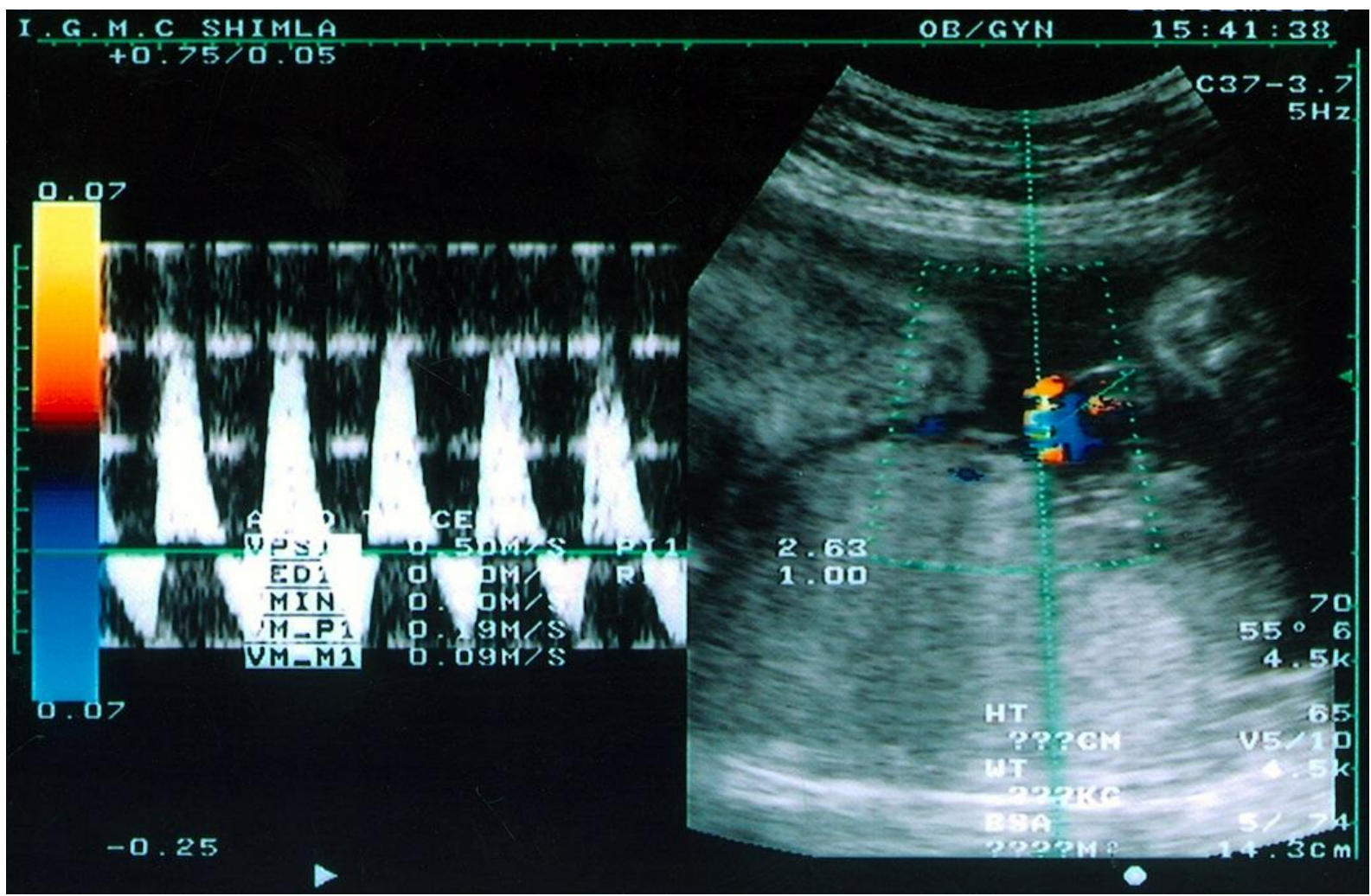

Case 2 - Reversed end diastolic velocity (REDV) in umbilical artery 


\section{Discussion}

IUGR affects $10 \%$ pregnancies and is associated with significant adverse perinatal outcome. Antenatal detection of fetus at risk remains a major challenge in obstetrics. Doppler velocimetry is used to evaluate hemodynamic adjustments arising in IUGR fetus. S/D ratio, PI and RI are the angle independent indices evaluated for knowing impedance to blood flow in the vessels.

S/D ratio of UA ranged from 3.2 at 28 weeks to 2.2 at 40 weeks. Trudinger $\mathrm{BJ}$ et $\mathrm{al}^{[3]}$ stressed the importance of S/D ratio. S/D ratio was raised in 34 cases out of 53 IUGR fetuses. Good perinatal outcome was reported in cases having normal S/D ratio. Schulman $\mathrm{H}$ et al found higher rates of LSCS for fetuses having increases S/D ratio. $81.5 \%$ were admitted in ICU and $15.7 \%$ perinatal deaths occurred amongst them. ${ }^{[4]}$

In our study raised S/D ratio of UA was found to be good predictor of adverse perinatal outcome. we found $13(52 \%)$ cases with raised S/D ratio in UA, out of which $11(84.6 \%)$ had operative delivery for fetal distress, $8(61.5 \%)$ were admitted to ICU and there were $3(23 \%)$ perinatal deaths. Sensitivity of raised S/d ratio was $78.5 \%$, specificity $81.8 \%$, negative predictive value $75 \%$ and positive predictive value was $84.6 \%$. The sensitivity was higher in our study. Lakhar BN et al ${ }^{[5]}$ reported specificity of $90-95 \%$ for raised PI. Our study also found raised PI of UA in 12 (48\%) cases, out of which $8(66.7 \%)$ were delivered by LSCS, low APGAR was seen in $4(33.3 \%)$ cases and $5(41.6 \%)$ were admitted to ICU. Perinatal deaths were reported in $3(25 \%)$ cases.

Marked increase in impedance leads to absent or even reversed end diastolic flow in UA. Such flows predict grave prognosis. VHM et al ${ }^{[6]}$, Trudinger BJ et al reported that IUGR fetuses had higher risk of absent or reversed end diastolic flow. The overall mortality was $28 \%$. ICU admissions were $96 \%$ for absent and $98 \%$ for reversed end diastolic flow. In our study $3(12 \%)$ cases had AEDV, all of them were born by LSCS and admitted to ICU. One neonate died after 5 days. Reversed end diastolic velocity was found in $1(4 \%)$ case which resulted in fresh still birth.

In response to prolonged fetal hypoxia, circulatory adaptation occurs to provide constant oxygen supply to brain, heart and adrenals, resulting in brain sparing effect.

Woo JS et $\mathrm{al}^{[7]}$ reported that $\mathrm{S} / \mathrm{D}$ ratio in MCA declined from $6.89 \pm 1.48$ at 25 weeks to $4.23 \pm$ 0.67 at term in normal pregnancies. In fetal hypoxia, when there is increased resistance to blood flow in $\mathrm{UA}$, there is decrease in impedance to blood flow in MCA leading to decrease in S/D ratio, PI and RI. We found $12(48 \%)$ cases with abnormal S/D ratio in MCA. LSCS was done for $9(75 \%)$ cases and there were $3(25 \%)$ perinatal deaths in this group. Positive predictive value of S/D ratio was $75 \%$.

Chandran R Serra VS et $\mathrm{al}^{[8]}$ reported that PI of MCA diminished significantly as gestation advances from 1.73 at 24 weeks to 1.38 at 39 weeks in normal pregnancies. Low PI in MCA was observed in $70.4 \%$ fetuses in complicated pregnancies. All hypoxic fetuses had low PI. Marri $\mathrm{G}$ et $\mathrm{l}^{[9]}$ reported $3(33.3 \%)$ deaths with abnormal PI values. In our study PI was abnormal in 17 (68\%) fetuses. Perinatal deaths occurred in 3 (17.6\%). 11 $(64.7 \%)$ fetuses were delivered by LSCS and 9 (52.9\%) fetuses were admitted to ICU.

Bahlman et al ${ }^{[10]}$ found RI of 0.8 at 28 weeks and 0.62-0.69 at 37 weeks of POG. Kirkinin et al reported increase in perinatal fetal risk in cases having low RI. In our study $8(32 \%)$ cases were found to have low RI in MCA. Low APGAR was seen in $5(62.5 \%)$ neonates and there were $2(25 \%)$ perinatal deaths. Weiner $\mathrm{Z}$ et al ${ }^{[11]}$, Forouzon et al ${ }^{[12]}$, Konje JC et $\mathrm{al}^{[13]}$ reported that in very severe hypoxia there was increase in PI of MCA reflecting brain oedema which had grave perinatal outcome. No such case was detected in our study.

Jouppila $\mathrm{P}$ et $\mathrm{al}^{[14]}$, Soothill $\mathrm{PW}$ et al reported that there was total end diastolic block in fetuses having chronic hypoxia. In our study 8 (32\%) fetuses were having raised S/D ratio in DTA, out of which 7 $(87.5 \%)$ were born by LSCS, $3(37.5 \%)$ neonates had low APGAR score, $4(50 \%)$ cases were admitted to ICU and there were $3(37.5 \%)$ perinatal 
deaths. In $2(8 \%)$ cases raised PI and RI was seen. Positive predictive value of S/D ratio was $87 \%$. There were 2 cases with AEDV, one of which was still born and another was born by LSCS and admitted to ICU.

\section{Conclusion}

Doppler velocimetry has higher predictive value for normal as well as abnormal perinatal outcome in IUGR fetuses. Early detection can improve the perinatal outcome and help the obstetrician to decide about the timing and mode of delivery so that premature delivery and related complications can be avoided.

\section{References}

1. Berkowitz GS, Mehalek KE, Chitkara U et al. Doppler umbilical velocimetry in the prediction of adverse outcome in pregnancies at risk for intrauterine growth retardation. Obstet Gynaecol 1988;71:742746.

2. Vyas S, Nicolaides $\mathrm{KH}$, Bower $\mathrm{S}$ et al. Middle cerebral artery flow velocity waveform in fetal hypoxaemia. Br J Obstet Gynaecol 1990;97:797-803.

3. Trudinger BJ, Giles WB, Cook CM. Flow velocity waveform in the maternal uteroplacental and fetal umbilical circulations. Am J Obstet Gynaecol 1985;152:155-163.

4. Rochelson BL, Schulman H, Fleischer A et al. The clinical significance of Doppler umbilical artery velocimetry in the small for gestational age fetus. Am J Obstet Gynaecol 1987;156:1223-1226.

5. Lakhar BN, Ahmed SA. Doppler velocimetry of uterine and umbilical arteries during pregnancy. Ind $\mathbf{J}$ Radiol Imag 1999;9:119-125.

6. KarsdorpVHM, van Vugt JMG, van Geijn $\mathrm{HP}$ et al. Clinical significance of absent or reversed end diastolic velocity waveforms in umbilical artery. Lancet 1994;344:16641668.
7. Woo JSK, Liang ST, Lo RLS et al. Middle cerebral artery Doppler flow velocity waveforms. Obstet Gynaecol 1987;70:613616.

8. Chandran R, Serra VS, Sellers SM et al. Fetal cerebral Doppler in the recognition of fetal compromise. $\mathrm{Br} \mathrm{J}$ Obstet Gynaecol 1993;100:139-144.

9. Mari G, Deter RL. Middle cerebral artery flow velocity waveforms in normal and small-for-gestational-age fetuses. Am J Obstet Gynaecol 1992;166:1262-1270.

10. Bahlmann F, Reinhard I, Krummenauer F et al. Blood flow velocity waveform of the fetal middle cerebral artery in a normal population: reference values from 18 weeks to 42 weeks of gestation. J Perinat Med 2002;30:490-500.

11. Weiner Z, Farmakides G, Schulman H et al. Central and peripheral hemodynamics changes in fetuses with absent end diastolic velocity in umbilical artery: correlation with computerised fetal heart rate pattern. Am J Obstet Gynaecol 1994;170:509-515.

12. Forouzan I, Tian ZY. Fetal middle cerebral artery blood flow velocities in pregnancies complicated by intrauterine growth restriction and extreme abnormality in umbilical artery Doppler velocity. Am J of Perinatol 1996;13:139-142.

13. Konje JC, Bell SC, Taylor DJ. Abnormal Doppler velocimetry and blood flow volume in the middle cerebral artery in very severe intrauterine growth restriction: is the occurrence of reversal of compensatory flow too late? $\mathrm{Br} \quad \mathrm{J}$ Obstet Gynaecol 2001;108:973-979.

14. Jouppila P, Kirkinen P. Increased vascular resistance in the descending aorta of the human fetus in hypoxia. $\mathrm{Br} \mathrm{J}$ Obstet Gynaecol 1984;91:853-856. 